\title{
PODER JUDICIÁRIO: 2014 É O ANO DO PLANEJAMENTO ESTRATÉGICO
}

Coluna publicada em 4.2.2014: <http://www.conjur.com.br/2014-fev-04/ contas-vista-poder-judiciario-2014-ano-planejamento-estrategico $>$

A segunda-feira (3/2) marcou a abertura formal do Ano Judiciário de 2014.

Trata-se de um ano especialmente relevante para o Poder Judiciário, e não é em razão de qualquer julgamento importante que se avizinha. Nem de questão jurídica, por mais estranho que possa parecer - e sim relacionada à Administração Pública e ao Direito Financeiro.

Neste ano serão tomadas as decisões que definirão os rumos do Poder Judiciário para o futuro, pois em 2014 elaborar-se-ão os planejamentos estratégicos plurianuais da maior parte dos tribunais do país.

O planejamento estratégico, como bem define o ministro do Supremo Tribunal Federal Ricardo Lewandowski, "consiste em antecipar racionalmente as açôes visando a atingir determinados objetivos do modo mais econômico possível. Significa, em suma, prever os distintos cenários que o futuro pode materializar, identificando, em tempo hábil, eventuais ameaças ou possíveis oportunidades"; significa "conceber um objetivo e coordenar todas as açōes para atingi-lo, integrando-as em um conjunto único. As açōes singulares, intermediárias, periféricas e circunstanciais, enfim, todas as ações, quaisquer que sejam elas, devem subordinar-se a um fim último colimado, evitando-se a dispersão de esforços". ${ }^{1}$ O planejamento estratégico do Poder Judiciário materializa-se em um documento no qual se definem a missão, a visão de futuro e os valores da instituição, fixando-se os objetivos estratégicos, com as respectivas metas, indicadores e as ações com as quais se pretende atingi-los.

1 Planejamento estratégico do Poder Judiciário. Revista Justiça \& Cidadania, nov. 2011, p. 17-18. 
Em 2009, foi publicada a Resolução 70 do Conselho Nacional de Justiça, que instituiu a obrigação para todos os tribunais de elaborar os respectivos planejamentos estratégicos, com abrangência mínima de cinco anos. Verdadeiro divisor de águas em matéria de administração do Judiciário, essa norma é a mais relevante para a modernização na gestão dos tribunais, inserindo-os no contexto de uma evolução pela qual vem passando a administração pública desde a década de 1990. Representou, como já escrevi anteriormente, "o início de uma nova e importante fase no planejamento da ação governamental, que é a transposição das técnicas de planejamento orçamentário, financeiro e administrativo para órgãos da administração pública", compatíveis com uma sociedade moderna que se torna cada vez mais dinâmica e exige uma administração competente, com ações eficientes, eficazes e efetivas. ${ }^{2}$

Considerando que a grande maioria dos tribunais instituiu seu planejamento pelo referido período mínimo, terão vigência nos anos de 2010 a 2014, encerrando-se, portanto, ao final deste ano.

Elaborar um planejamento estratégico é tarefa complexa, pois exige pesquisas, estudos e análises minuciosos, discussões com os interessados, ouvindo-se todos aqueles que integram o órgão e também os cidadãos, que são os beneficiários finais de sua atividade, para que sejam estabelecidas democraticamente as prioridades que melhor reflitam o interesse público. Sopesar todas essas informações, à luz das mais modernas técnicas de administração pública, para elaborar um documento que represente fiel e efetivamente as diretrizes a serem seguidas e que seja dotado de legitimidade e credibilidade, de modo a engajar todos os seus integrantes na busca dos resultados almejados, requer tempo, trabalho e dedicação. Necessário, pois, canalizar as energias durante este ano para cumprir esta que será a mais importante tarefa do Poder Judiciário.

Sabe-se que o que mais falta na administração pública, e nela os tribunais não são exceção, é boa gestão, e melhorar a administração com a implementação de métodos mais modernos é a área em que há mais espaço para grandes avanços. ${ }^{3}$

$\mathrm{O}$ primeiro e mais relevante passo para qualquer administração, pública ou privada, que almeje obter bons resultados, é o planejamento sério e bem elaborado, pois é nele que constam as diretrizes, objetivos e metas a seguir, sem o que toda a

2 CONTI, José Mauricio. Planejamento e responsabilidade fiscal. In: SCAFF; CONTI (orgs.). Lei de Responsabilidade Fiscal - 10 anos de vigência. Florianópolis: Conceito Editorial, 2010, p. 52-53.

3 Veja coluna publicada neste mesmo espaço em 31 de julho de 2012, com o título Não falta dinheiro à administração pública, falta gestão. 
gestão fica sem sentido. São muitas as demandas, inúmeros os interesses e interessados; não havendo prioridades estabelecidas com critério, o gestor não tem parâmetros para tomar suas decisóes. A partir do plano traçado, é que se elaboram os projetos, que passam a ter coerência, coesão e integração. Governar sem um bom planejamento "é como comandar um transatlântico no meio do oceano sem mapa, instrumentos de navegação e, principalmente, sem saber o porto de destino. Pouco importa cuidar da adequada limpeza, funcionamento da cozinha, da casa de máquinas e tudo o mais que é necessário, se o navio está verdadeiramente à deriva, pois o comandante sequer sabe para onde vai", já escrevi anteriormente. ${ }^{4}$

No caso da Administração Pública, a responsabilidade é ainda maior, pois se lida com dinheiro público, e a falta de planejamento resulta invariavelmente em grandes desperdícios de recursos que pertencem a todos nós.

Em se tratando do Poder Judiciário, há que se dar especial relevo por ser a principal instituição na administração da Justiça. Decisões e ações do Poder Judiciário afetam e conduzem os demais órgãos, pessoas e instituições essenciais à Justiça. É por iniciativa do Poder Judiciário que se define a instalação de novos fóruns e comarcas, é ele quem conduz os processos e, mais recentemente, implanta sistemas de processo eletrônico aos quais terão de se adaptar o Ministério Público, a Defensoria, a Advocacia, auxiliares da Justiça e os cidadãos. Daí porque se torna mais relevante o planejamento de seu futuro e suas açôes, tornando-os transparentes e previsíveis, a fim de que todos que dele dependam e com ele se relacionam possam também se planejar.

Poucos se dão conta, mas vários dos tribunais que integram o Poder Judiciário de todo o país têm dimensões que superam muitos estados da Federação e a maior parte dos municípios. Para que se tenha uma noção, o Tribunal de Justiça de São Paulo, o maior do país, tem orçamento para este ano de 2014 da ordem de $\mathrm{R} \$ 8,4$ bilhões, praticamente equivalente ao dos estados de Alagoas e Sergipe ( $\mathrm{R} \$ 8,3$ bilhôes e R \$ 8,2 bilhôes, respectivamente), e maior do que os orçamentos dos estados do Acre, Amapá, Roraima e Rondônia, e do de cidades como Curitiba, Fortaleza e Salvador, além de superar o de órgãos como o Senado, a Câmara dos Deputados e o Ministério Público da União. Não é razoável que todos os entes da federação sejam obrigados a ter um planejamento de médio prazo, como o plano plurianual

4 Coluna Planejamento municipal precisa ser levado a sério, publicada em 24 de setembro de 2013.

5 Todos os dados em valores aproximados, em bilhōes de reais, referentes ao orçamento de 2014: Acre - 5,3; Amapá - 5,1; Roraima - 2,9; Rondônia - 6,9; Curitiba - 7,6; Fortaleza - 6,4; Salvador - 6,4; Senado - 3,8; Câmara dos Deputados - 4,9; e Ministério Público da União - 4,7. 
previsto no art. 165, I, da Constituição, e não se exigir o mesmo para os Tribunais. São eles, atualmente, órgãos da Administração Pública cujo tamanho e complexidade tornam imprescindível, ainda que integrando um ente federado, seguir as mesmas exigências a que somente estes últimos estavam formalmente sujeitos. ${ }^{6}$

Criado em 18 de março de 2009 pela já mencionada pela Resolução 70 do CNJ, o planejamento estratégico vigente não foi construído com a perfeição desejável em todos os tribunais, não só pela exiguidade do prazo - menos de um ano -, como também, e principalmente, pelo pioneirismo da experiência, inovadora na quase totalidade dos tribunais. Neste ano, com a experiência adquirida e os dados coletados, todos terão a oportunidade de aperfeiçoá-lo, superando as dificuldades do anterior e produzindo um documento que é fundamental para uma gestão que se pretenda moderna e eficiente.

Assim é que os tribunais, com o apoio dos respectivos Núcleos de Gestão Estratégica (Res. CNJ 70/2009, art. 30), devem elaborar e implementar este novo planejamento estratégico, com a participação efetiva de serventuários e magistrados de primeiro e segundo graus (idem, art. $2^{\circ}, \$ 4^{\circ}$ ), assegurando alinhamento com os respectivos orçamentos, de forma a garantir os recursos necessários à execução (idem, art. $2^{\circ}, \$ 3^{\circ}$ ). Além de assegurar os recursos orçamentários, há que se compatibilizar o planejamento estratégico com o plano plurianual do respectivo ente da Federação que integram, evitando incongruências e inconsistências que mitiguem sua credibilidade e prejudiquem a execução, controle e fiscalização.

No Poder Judiciário, o planejamento, ao menos de médio prazo, tem relevância maior do que em outros órgãos da administração. Isso se deve, especialmente, ao curto mandato de seus presidentes, fixado em dois anos pela Lei Orgânica da Magistratura Nacional, insuficiente para que tomem adequado conhecimento da máquina administrativa e possam, neste espaço de tempo, elaborar, implementar e gerir projetos novos. Essa frequente alternância dos gestores pela exiguidade no tempo do mandato torna ainda mais importante um planejamento dotado de segurança jurídica, dada a necessidade de continuidade administrativa ${ }^{7}$ e de um sistema eficiente de gerenciamento de projetos.

6 "Somadas essas e outras circunstâncias à dimensão de alguns órgãos da administração pública, esta só poderá ser eficiente se as técnicas de planejamento forem aplicadas também a esses órgãos, especialmente aqueles dotados de alto grau de autonomia, em que se torna pouco viável a imposição de normas e procedimentos. É o caso, por exemplo, dos Poderes da República, dos Ministérios Públicos e dos Tribunais de Contas", já escrevi em Planejamento e responsabilidade fiscal..., op. cit., p. 52-53.

7 Vide os "considerandos" da Resolução 70/2009. 
Acrescente-se que, nos tribunais, o cargo de cúpula cabe a um magistrado, do qual não se exige formação nem prática em administração pública, como também ocorre com os entes federados de forma geral. Estes últimos, no entanto, contam, no mais das vezes, com quadros técnicos permanentes especializados em gestão pública, e seus mandatários exercem o cargo por quatro anos, facultada a reeleição, o que não ocorre nos tribunais.

Não se deve esquecer ainda que podem ser aproveitadas as experiências dos demais tribunais com os projetos bem-sucedidos do banco de boas práticas de gestão do Poder Judiciário do Conselho Nacional de Justiça, ${ }^{8}$ e com ele colaborar, inserindo os projetos exitosos para que sejam também utilizados pelos outros tribunais.

O Poder Judiciário, hoje, está cada vez menos isolado, interage com os demais, interfere no orçamento público impulsionando políticas públicas em um ativismo judicial que é crescente e participa de forma intensa nas áreas da saúde; educação; proteção à criança e ao adolescente, a idosos e deficientes; e em programas que envolvem todos os entes da federação, transformando-se no "grande protagonista da cena estatal neste início do século 21”, como bem observou o Desembargador José Renato Nalini, presidente do Tribunal de Justiça de São Paulo, em artigo recente.?

Vê-se que não será fácil. Coordenar tudo isso é uma tarefa complexa, não tenham dúvidas. Mas o Poder Judiciário exerce, hoje, papel fundamental para que o país atinja os objetivos expressos no artigo $3^{\circ}$ da Constituição, agindo em harmonia com os demais poderes, nos termos do artigo $2^{\circ}$. E planejar é o primeiro e principal passo nessa missão que precisa ser cumprida, ainda que pareça, à primeira vista, muito difícil.

Mas sonhar nunca é demais. E "os magistrados também devem sonhar. Sonhar com um Judiciário forte e unido que ocupe o lugar de destaque que seus membros merecem no cenário social e político deste País, para que possam, em conjunto e individualmente, colaborar de modo efetivo na construção de uma sociedade mais livre, mais justa e mais solidária”. ${ }^{10}$

8 Res. CNJ 70/2009, idem, artigo 40 - <http://www.cnj.jus.br/estrategia/index.php/boaspraticas/>.

9 O que esperar da Justiça? O Estado de S.Paulo, 2 de janeiro de 2014, p. A2.

10 Min. Ricardo Lewandowski, Planejamento estratégico do Poder Judiciário, op. cit., p. 19. 
